\title{
TEMPORAL DISCLOSEDNESS OF INNOVATIONS
}

\author{
Understanding Innovation Trajectories in Information \\ Infrastructures
}

Edoardo Jacucci

Department of Informatics, University of Oslo, Norway

\begin{abstract}
The paper addresses the research question of how to analyze and evaluate innovations in complex information infrastructures. Recent studies of innovation processes involving standard-based networking technologies have called for new theoretical insights than the ones provided by traditional studies on Diffusion Of Innovations. Understanding this type of innovations becomes particularly difficult in the context of complex information infrastructures. Based on the empirical material from a case study of an IS innovation in a Norwegian hospital, the paper provides insights on temporal aspects of innovations. The paper makes two key contributions to the ongoing discussion. It introduces the concept of temporal disclosedness, which describes the tendency of innovations to disclose along the past, present, and future trajectory of the infrastructure, breaking traditional analytical and temporal boundaries. Secondly, with the help of this concept, it shows how some of the current theoretical approaches may be adequate to study the disclosedness of innovations, but their use is currently limited and hence should be extended.
\end{abstract}

Key words: Innovation, Time, Information Infrastructure

\section{INTRODUCTION}

This paper is concerned with the conceptualization of innovation in information systems (IS) (Kwon \& Zmud 1987; Cooper \& Zmud 1990; Baskerville \& Pries-Heje 1997; McMaster et al. 1997). Innovation here refers to the process of implementation of a new idea in an organizational setting (Van de Ven 1986). In particular, the paper addresses the question of 
how innovations implemented in complex infrastructures of interconnected IS should be analyzed and evaluated (Hanseth et al. 1996; Damsgaard \& Lyytinen 1997). Recent discussions have raised the need to find new theoretical approaches to understand the complexity of such innovation processes (McMaster et al. 1997; Lyytinen \& Damsgaard 2001). Examples of the complexity can be found in the difficulty in evaluating the success or failure of an infrastructural innovation; for instance, the difficulty to temporally and spatially isolate it from the surrounding context. When implemented, the type of innovations at case become largely dependent from the existing context, are often subject to frequent re-planning, and in some cases never seem to end. As a response, this paper aims to contribute to the ongoing discussion by focusing the attention on the study of temporal aspects of innovations. It investigates how innovations relate to the context before, during, and after its complete or incomplete implementation. The paper also discusses how approaches to the study of innovations have thus far come short in addressing in particular the influence of innovations on the future trajectory of the surrounding infrastructure.

Analyzing a case study on an innovation implemented in a large Norwegian hospital, the paper illustrates how understanding these temporal aspects is paramount to the study of the innovation. More specifically, the case deals with the implementation process of an Electronic Patient Record (EPR) system in a Norwegian hospital. The case shows how, in order to understand the dynamics of the innovation, the analysis must include the study of the context (the surrounding infrastructure) in the time before and during the implementation. Additionally, the analysis must investigate the influence of the implemented innovation on the generation of future innovations.

Based on the empirical evidence of the case, and by introducing the concept of temporal disclosedness, the paper aims to illustrate how innovations in complex information infrastructures tend to break analytical, temporal and spatial boundaries, and disclose along the entire trajectory of the infrastructure. Hence, the paper suggests that evaluations of innovations in complex information infrastructures take into consideration this particular property by extending their analysis beyond apparent temporal and spatial boundaries. The analysis of the case presented in the paper provides a practical example.

The paper is structured as follows. First, a reasoned review of recent literature on the study of innovations in IS is provided. Secondly, the methodology of the study conducted is illustrated. Thirdly, the case description will provide the empirical evidence for the subsequent discussion. Finally, conclusions are drawn summarizing the main message of the paper. 


\section{THEORETICAL FRAMEWORK}

This paper aims to contribute to the ongoing discussion on how to conceptualize innovation in the context of Information Systems (IS) implementation (Kwon \& Zmud 1987; Cooper \& Zmud 1990; Baskerville \& Pries-Heje 1997; McMaster et al. 1997). In particular, similarly to the work by Lyytinen \& Damsgaard (2001) it is concerned with innovations involving complex standard-based networked technologies in large organizations. Additionally, it adopts the perspective of technology as suggested by Hanseth et al. (1996) whereby technology is not seen as isolated from its social-technical context. Accordingly, IS innovation can not be considered as the implementation of isolated pieces of technology: it is rather a process of continuous negotiation and re-appropriation of the existing installed base (Hanseth et al. 1996; Monteiro \& Hepsø 1998).

The paper will try to focus the attention of the current discussion on aspects of temporality in innovations by addressing the following research question: how does the innovation relate to the past, present, and future of its lifecycle and to the surrounding infrastructure in which it is implemented?

To address this question, we will first identify two main streams of theoretical works in the field. Then we will briefly discuss their temporal conceptualization of the innovation. Finally, we will provide the background and motivation to elaborate the theoretical contribution in the discussion section.

\subsection{A review of research in IS innovation}

Adapting a framework proposed by Wolfe (1994) in her study of organizational innovations, the field of IS innovation may be categorized in the two research streams of stage-model and process-model innovation process theories. Accordingly, while more traditional Diffusion Of Innovations (DOI) studies seem to address the question of "What is the pattern of diffusion of an innovation through a population of potential adopter organizations?", process theory approaches (stage-model and process-model) tend to address the question of "What are the processes organizations go through in implementing innovations?". In turn, each of the two research streams reinterprets this question by either focusing on the identification of implementation stages (stage-model research) or by analyzing the chain of events resulting in the innovation implementation (process-model research) (ibid.).

The review will first provide an overview of selected works in the stagemodel research stream. Following this, the process-model stream will be presented. It is worth noting how this research in the IS field, although not 
purely DOI research according to Wolfe (1994), has traditionally been heavily influenced by the theoretical frameworks of DOI research (Rogers 1995). Examples of such studies are Cooper \& Zmud (1990), Fichman \& Kemerer (1999), and Gallivan (2001). In each of these interesting works the researchers seem, on the one side, embrace the DOI framework, and yet on the other side struggle with its clear limitations when applied in the context of complex IS. As a result, in one case the model consistently describes the adoption and infusion processes only if the innovation has a low complexity (Cooper \& Zmud 1990). In another case, the struggle resulted in the need to refine the too generic stage model by Rogers (1995) into a more sophisticated one involving primary and secondary adoption (or voluntary and mandatory) (Gallivan 2001). In a third case, the researchers strived to go beyond the appearance (or illusion) of diffusion of an IS innovation, by measuring the often elusive and invisible gap between acquisition of an innovation and its factual deployment (Fichman \& Kremer 1999).

Despite the clear attempt to overcome theoretical shortages of the DOI framework, these kinds of studies tend to remain within that framework. Yet, they differ from more classical DOI studies in their focus on the postadoption phase of the innovation. In particular they tend, in line with DOI theories, to model the innovation in distinct (though possibly overlapping) stages.

A second set of studies on IS innovation is the process-model innovation process theory research stream (Wolfe 1994). These studies often recognize the limitation of the DOI framework and adopt alternative frameworks with the clear intention to dive into the messiness of the innovation process without the urge to model it in distinct stages (Lyytinen \& Damsgaard 2001; McMaster et al. 1997; Attewell 1992).

For instance, Swanson \& Ramiller (1997) introduce the notion of organizing vision in IS innovation providing an institutional view of how a "[...] collective, cognitive view of new technologies enables success in information systems innovation [...]" (ibid.). Other works indirectly contribute to the conceptualization of IS innovation as a mutual adaptation of technology and organization (Leonard-Barton 1988) or as sense-making of IT adaptation (Weick 1995; Henfridsson 1999).

Other researchers have focused on the role of organizational learning (Attewell 1992), or of formative contexts (Ciborra \& Lanzara 1994). In these studies innovation is defined as the learning process of the organization in a particular context and in this sense independent of the technology. Ciborra also interprets the appropriation of a Groupware application in an organization as a process of taking care of the innovation (Ciborra 1996). This latter conception pushes the study of IS innovation in the philosophy of existentialism (Heidegger 1962). 
A more recent stream of research developed the concept of "interactive innovation" (Rothwell 1994; Newell et al. 2000; Newell et al. 1998). This concept contributes to the conceptualization of innovations as the emergent process of knowledge exchange among inter- and intra- organizational networks. From this perspective, innovations are seen as the "[...] interaction of structural characteristics of organizations and the actions of individuals" (Newell et al. 1998).

Finally, other studies on IS innovation have adopted the conceptual framework of Actor Network Theory (ANT) (Latour 1987; McMaster et al. 1997; Monteiro \& Hepsø 1998). For instance, Aanestad \& Hanseth (2000) conceptualize the implementation of an open network technology as the cultivation of a "hybrid collectif" of humans and non-humans, technologies and non-technologies.

These studies share the interest of understanding the process of innovation as it unfolds, and not as the completion of a stage process. Accordingly, drifts, deviations, and complexities are not feared, rather are acknowledged and included in the analysis and theorization.

Specifically, the contributions by Lyytinen \& Damsgaard (2001), and Monteiro \& Heps $\varnothing$ (1998) regarding the diffusion of complex infrastructural innovations are particularly relevant for the case discussed in this paper. These two works open the discussion of IS innovation to address aspects of complexity: innovations are considered embedded in their organizational context where the existing socio-technical network has a great influence on the unfolding of their process. In this context, phenomena such as pathdependence (Arthur 1994; David 1985), lock-in (Arthur 1989), network effects (Antonelli 1992), and drift (Ciborra 2000) due to the existing installed base, tend to influence the trajectory of the innovation (Dosi 1982; Hanseth et al. 1996). In this sense, aspects of complexity are inherent to the infrastructural nature of IS innovation.

As the case study presented further in the paper will suggest, this is an area of discussion which needs to be expanded and which requires deeper understanding of the innovation phenomena.

\subsection{On the current temporal conceptualization of innovation}

The aim of this section is to unfold how the two broad research streams, stage-model and process-model, deal with the temporal aspects of innovation. Specifically, we mean to unveil the discourse about temporality in the two streams focusing on the three temporal analytical categories of past, present, and future. 
The past category refers to the past heritage of the context where the innovation is implemented. The first research stream tends to overlook or underestimate the role of the past in the conceptualization of innovations when analyzing complex IS. The past, or the initial situation where the innovation needs to be adopted, is conceptualized as a stage which needs to be unfreezed, changed, and refreezed to implement the innovation (Kwon \& Zmud 1987; Lewin 1952). It is therefore taken for granted that there is a beginning or an initiation of the innovation, which is a particular point in time where the innovation starts with a clear cut from previous events.

On the other hand, the second research stream often adopts theoretical frameworks which explicitly take into consideration the influence of the past in the implementation effort of the innovation. For example, studies on organizational learning using concepts such as double-loop learning (Argyris \& Schön 1996) or formative contexts (Ciborra \& Lanzara 1994), underline the relevance of existing cognitive structures and knowledge in the process of innovation. Other studies in this stream adopt ANT to take into account the role of the past showing how strength of inscriptions, black boxing, and irreversibility contribute to the shaping and establishment of socio-technical networks (Latour 1987; McMaster et al. 1997; Monteiro \& Hepsø 1998).

As for the relation of the innovation with the present, the question remains as to the extent to which the implementation is regarded as realization of a "[...] 'black box' of readily available technological possibilities [...]" or as an emergent and open process or trajectory (Dosi 1982). According to the first research stream, the innovation unfolds in stages which have a logical order. Independent from the sophistication in quantity, quality, or temporal arrangement of the stages, the assumption of the stage-model is the possibility of reaching a closure of the innovation where predicted benefits are achieved.

In the second research stream the implementation process is often seen as emergent (Leonard-Barton 1988), context-dependent (Ciborra \& Lanzara 1994), continuously negotiated (Monteiro \& Hepsø 1998), or interactive (Robertson et al. 1996). Thus the range of possibilities of the innovation is continuously re-invented, re-negotiated, re-contextualized and reappropriated undermining the closure of the implementation according to predicted benefits, and opening for potentially new ones.

Finally, the relation of the innovation with the future concerns the effects of the innovation on the future development of the surrounding context. In our particular case, it regards the role of the innovation in influencing the future trajectory of the infrastructure. Studies based on DOI limit their temporal scope to their unit of analysis: the particular innovation process. Hence no account of evaluation of the innovation on the future development of the context in which it is implemented is provided. Studies in the second 
research stream also seem to come short in addressing this temporal dimension. That is, the analysis and evaluation of the innovation is also in this case focused on the "event" of the implementation rather than on the influence of such implementation on future innovations.

On this point, the information infrastructure (II) perspective as proposed by Hanseth (et al. 1996) provides useful insights. By conceptualizing the complex system of interrelated IS in an organization as an II, the critical role of the installed base in the development of the existing socio-technical network is put forward. This conceptualization acknowledges the role of the past (e.g. of path dependence) in the current shaping of the II. This implicitly points at the importance of considering the innovation process itself as a process contributing to the shaping of the new installed base influencing future innovation. It is consequently relevant to consider the present innovation in the light of future possible developments of the II.

In the case and discussion sections of this paper, we will illustrate how the temporal dimension of the future is crucial to the understanding and evaluation of the innovation discussed. We will then elaborate in more detail a temporal conceptualization of the innovation in II by introducing the concept of temporal disclosedness.

\section{METHODOLOGY}

The research reported in this paper is grounded in the interpretive approach to case study in IS (Klein and Myers, 1999; Walsham 1993, 1995). The research was guided by the following general question: "What are the complexities involved in the implementation of a standard-based technology in the setting of a hospital information infrastructure?". The fieldwork has been conducted over a period of over two years, from October 2001 to the present. Ethnographically inspired methods were employed for data collection, including 32 interviews with doctors, nurses, secretaries and IT managers, 8 instances of observations of daily work and users training sessions, documents analysis, and participation in several discussion meetings. The interviews were recorded on MiniDisc $\odot$, the most relevant (about 30\%) have been transcribed and circulated among the research group. The others have been re-listened and summarized. The research group consisted of two Ph.D. students (including the author) a lecturer and a professor. After coding and discussions, the data has been analyzed by organizing it in process narratives (Langley 1999). A second round of analysis was used for theorization (e.g. production of this paper). The head of research of the IT department of the hospital joined regularly these 
meetings to update the research group on the project, and to suggest interesting area for further research.

Concerning the use of theories, the process of theorizing from the collected process data was inspired by the study of temporality in the existential philosophy of Heidegger (1962). In doing so we acknowledge the risk of appropriating a concept or perspective in a different theoretical milieu than the one in which it was conceived. We do in fact recognize that, if inspired by Heidegger, the study of temporality should not be detached from a study of the state-of-mind (Befindlichkeit in German) (Heidegger 1962: p.389; Ciborra 2002). Nevertheless, we find that our appropriation of the concept is adequate as we see the current paper as a step towards the breaking-down of misleading metaphysical categories.

\section{CASE DESCRIPTION}

The case illustrates the nature and the context of an IS innovation implemented in a major Norwegian hospital (referred to as NorHospital). Specifically the innovation regards the implementation of a hospital wide clinical information system called Electronic Patient Record (EPR). The EPR represents a networking technology which aims to standardize and centralize the structuring, storing, and use of patient related clinical information in the entire hospital.

In order to provide the necessary historical and contextual perspective, the case describes three analytical stages of the development of the Information Infrastructure (II) in NorHospital; the second stage being the one when the EPR was conceived and implemented. The aim is to provide an account of the three different stages as three different technological paradigms (Dosi 1982).

We will now provide some contextual information regarding the hospital and the role of its IT department.

NorHospital is a large University hospital. It is the second largest hospital in Norway, with approximately 600 beds, 4000 employees and an annual budget of 2.5 billion NOK (around 360 million US Dollars). In 2002 more than 193'000 patients were treated.

The role and function of the IT department in NorHospital have considerably shifted from purely technical support in early 90s, to encompass "high-risk" clinical information systems development. At the beginning of 1990s the IT departments' staff was approximately 20 persons on a budget of approximately 10-15 MNOK. Currently over 80 people are running projects on a budget around $80 \mathrm{MNOK}$. Moreover, for the next four years (2003-2006), the IT department has set up a budget of 267 MNOK 
alone for development and implementation of clinical information systems. There are currently requests to raise the budget to as much as $500 \mathrm{MNOK}$. The budget for similar projects before 1995 was 0 MNOK. Moreover, in the last decade the scope of intervention of the IT department has changed from being a "technical problems solving" department to act as a service department, oriented towards the needs of their "customer": the different hospitals departments. Finally, after a health sector reorganization in Norway, the department started to address new "customers" outside the hospital. Indeed, during the last year, the department has been active in positioning itself as a regional actor in providing services related to clinical information systems.

\subsection{LAN: From Mainframe to PC}

We will now describe the first of the three analytical stages of the development of the infrastructure: the transition from a Mainframe to a LAN and PC infrastructure.

In early 1990s the information infrastructure at the hospital was primarily based on a few mainframe systems used for administrative purposes. Examples of applications were a Patient Administrative System, Human Resource management systems and a financial system. Accordingly, competencies in the IT department were limited to technical knowledge, and the type of service provided was rather routinized. At this time there was no involvement of the IT department in any activity related to clinical information.

Around mid 1990s the IT department installed a Local Area Network (LAN) and started to diffuse the first Personal Computers (PC). As a consequence, some clinical departments started to develop local systems. The systems were usually developed by doctors who were also amateur programmers and were usually serving local needs of organizing and storing data. Most of these systems have survived until today and represent an important and efficient part of several clinical departments' practices. They were often used as local Electronic Patient Record (EPR) systems, sometimes with statistical functionality for research purposes. The systems were developed entirely inside the departments without any support from the IT department, apart from providing the basic infrastructure. Also in this transition of the infrastructure from mainframe-terminal to LAN-PC the role of the IT department was merely one of technical support and maintenance. 


\subsection{EPR: Centralization and Tight Integration}

In this section we will describe the second stage of the development of the infrastructure: the flourishing of clinical information systems and the implementation of the centralized EPR.

It is not until 1995 that the IT department faced the need to embrace new challenges in the uncharted area of clinical information systems. During that year a considerable amount of new projects were started, alongside the traditional technical support and maintenance activity. The new projects included the development of four new laboratory systems, a Radiology Information System (RIS), and a picture archive system for x-rays (PACS). Moreover, in the same year an EPR project was started with the aim of developing a hospital-wide centralized clinical information system. The aim of the project (which was done in cooperation with four other regional hospitals) was to develop a centralized version of an EPR substituting the locally developed EPR and integrating it with the other clinical systems. The project was supposed to last three years with the vendor delivering the final version of the EPR by the end of 1999 and the IT department implementing the EPR to reach 3500 potential users. As of now, all users have been reached, but the final version has not yet been delivered, while the version currently implemented is covering only about $30-40 \%$ of the requested functionality. Moreover, local EPR are still being used, and integration with clinical systems is partial or non-existent.

Reasons for the delay and the limited implementation may be found in the complexity of the design of a standardized and centralized EPR; in the complexity of the integration process with local clinical systems (complexity which involves political and power issues besides purely technical ones); and in an overall vendor-dependent strategy of reaching for perfection.

At the time the EPR project was started the IT department consisted of 19 people including two developers. None of these people had any formal background in clinical practice and thus were not ready to take on such risky projects. However, the IT department began to systematically acquire competencies and resources in order to manage the new type of projects. For the development of any new clinical information system, a project manager from the clinical department was appointed, and some end-users were involved part-time in the project.

With the EPR and other clinical systems, the IT department started to deal with projects with an increasing complexity. Some of them were rather straightforward, others required far more time and resources than planned (e.g. the development of PACS and of the EPR). All of them required innovative ways of working. One key element was interdisciplinarity and coresponsibility. As a consequence, an increasing number of people working in 
clinical departments moved to the IT department covering key positions in development projects. The scope of the IT department was expanding from supporting administrative systems to also developing and implementing clinical systems. At the same time, the core competence was shifting from purely technical knowledge to an interdisciplinary approach to the design, implementation and adaptation of clinical information systems.

With the EPR project the range of action and influence of the IT department definitely reached the width of the entire hospital organization and the depth of the complex clinical work-practices.

\subsection{CSAM: Layering and Loose Integration}

The development and implementation of the hospital wide EPR proved more difficult and complex than predicted. Despite the considerable change in staff, competence, and resources, the IT department of NorHospital seemed incapable of meeting some of the challenges that the vision of the EPR had inscribed in its conception. In particular, the EPR was seen as the central system meant to substitute all local systems. Furthermore, it was supposed to integrate all the information in one standardized format, while until then the information was handled, stored and structured according local standards. Finally the vision of the EPR was to provide a single solution to a variety of often contradicting requirements. For example, the EPR had to fulfill users' needs, while satisfying divergence of opinions in the different professions of the users (e.g. doctors and nurses), and disciplines (in almost each medical discipline there is an international standardization committee concerned with the structuring of their clinical information). Additionally it had to comply with national laws and regulations regarding information security, patient privacy, and the definition of the legal documentation of the patient treatment.

The idea of implementing the "one" standardized and centralized clinical system was slowly being substituted by the idea that the implementation of the EPR was the "Art of the impossible!" (in Norwegian: Det umuliges kunst!; cited from a presentation by a manager at the IT department). The understanding of the information infrastructure of the hospital as a puzzle of systems was leaving the stage to a more "systemic" view; that is a view of a complex lattice of interconnected systems, practices, power relations, and acquired knowledge.

At this point, the leadership at the IT department sentenced the idea of the holistic ERP to death, instead replacing it with a new vision focusing on services. The new vision was labeled Clinical Systems All Merged (CSAM) and may briefly be summarized as follows: 
- Focus on information services instead of information containers (such as the EPR)

- CSAM is a process: focus on delivery of tangible benefits (e.g. better coordination between two departments) rather than of particular products (e.g. the EPR)

- Stepwise bottom-up approach leveraging existing resources rather than top-down long term planning

- Bottom-up approach responding to factual emergent needs of services

- Technological solution based on portal technology: layering and loose integration

- Increased control over direction of development, e.g. by

- Increased independency from vendors: vendors provider of tool-box technology instead of complete solution (as with EPR)

Along with a Norwegian proverb, the motto which facilitated the transition was: "The best is enemy of the good!" (in Norwegian: Det beste er det godes fiende!; citation from interview with a manager of CSAM). In this motto the EPR vision was seen as the ideal (i.e. the best) solution which proved impossible to reach. The CSAM philosophy, on the contrary, aimed at providing a good enough solution, although probably not the best, but achievable in a reasonably short time and with available resources.

\section{DISCUSSION}

We will now proceed with the analysis of the case with the aim to highlight how the implementation of the EPR related to the past, present, and future of the trajectory of the information infrastructure. We will first provide an interpretation of the three stages as three technological paradigms (Dosi 1982). Then we will discuss the extent to which the reviewed theories on innovation can provide insights in the case, highlighting their structural limitations or their limited use. Finally we will introduce the concept of temporal disclosedness to underline the particular temporal characteristic of innovations in the context of information infrastructure, and will accordingly suggest the direction of research in similar cases.

\subsection{Three paradigms and their relation}

The following table summarizes the three analytical stages of the management of the Information Infrastructure at NorHospital (Table 1).

Each of the stages represents a different paradigm of strategy, management, and technology which shapes the trajectory of the infrastructure (Dosi 1982). In order to comprehend the dynamic of this 
trajectory, it is important to identify the influence of each paradigm on the next. Many of the elements are external to the context of the hospital (e.g. advances in networking technologies, the diffusion of the internet as technology and as a technological paradigm, the development of user interface technologies, laws and regulations, health reforms etc...), yet still there are several internal elements which have a great influence in the future trajectory of the infrastructure.

Table 1. Three paradigms in the management of the Information Infrastructure

\begin{tabular}{|c|c|c|c|}
\hline Dimensions & $\overline{\text { LAN }}$ & EPR & CSAM \\
\hline $\begin{array}{l}\text { General Strategy } \\
\text { (IT dpt.) }\end{array}$ & Nobig strategy & $\begin{array}{l}\text { Long term } \\
\text { focus: achieve } \\
\text { complete } \\
\text { integration and } \\
\text { standardization }\end{array}$ & $\begin{array}{l}\text { Short term focus: } \\
\text { achieve benefits on } \\
\text { focused and emergent } \\
\text { needs using available } \\
\text { resources }\end{array}$ \\
\hline $\begin{array}{l}\text { Competence } \\
\text { (ITdpt.) }\end{array}$ & Technical & $\begin{array}{l}\text { Technical + } \\
\text { Clinical }\end{array}$ & Technical + Clinical \\
\hline $\begin{array}{l}\text { Business Model } \\
\text { (IT dpt.) }\end{array}$ & $\begin{array}{l}\text { Maintenance and } \\
\text { Support }\end{array}$ & $\begin{array}{l}\text { Delivery of } \\
\text { solution } \\
\text { (product focus) }\end{array}$ & $\begin{array}{l}\text { Provision of } \\
\text { information services } \\
\text { (process focus) }\end{array}$ \\
\hline $\begin{array}{l}\text { Management Style } \\
\text { (IT dpt.) }\end{array}$ & Routine management & $\begin{array}{l}\text { Traditional } \\
\text { project } \\
\text { management: } \\
\text { hierarchies, } \\
\text { planning, heavy } \\
\text { documentation }\end{array}$ & $\begin{array}{l}\text { "Creative" } \\
\text { management: } \\
\text { emergent, informal, } \\
\text { dynamic }\end{array}$ \\
\hline Role of Users & Almost none & $\begin{array}{l}\text { Ideally } \\
\text { participation of } \\
\text { the whole user } \\
\text { base }\end{array}$ & $\begin{array}{l}\text { User base involvement } \\
\text { secondary: heavy use } \\
\text { of acquired knowledge } \\
\text { from EPR } \\
\text { implementation }\end{array}$ \\
\hline $\begin{array}{l}\text { Main Role of } \\
\text { Vendor }\end{array}$ & $\begin{array}{l}\text { Provider of } \\
\text { infrastructural } \\
\text { components (cables, } \\
\text { computers etc...) }\end{array}$ & $\begin{array}{l}\text { Provider of } \\
\text { Complete } \\
\text { Solution (high } \\
\text { dependency on } \\
\text { vendor) }\end{array}$ & $\begin{array}{l}\text { Provider of } \\
\text { infrastructural } \\
\text { components (portal } \\
\text { technology, database } \\
\text { systems etc...) (lower } \\
\text { dependency on } \\
\text { vendor) }\end{array}$ \\
\hline
\end{tabular}

First, the radical change from the LAN to the EPR paradigm was mostly influenced by external factors. Yet, one determinant internal aspect of the LAN paradigm was the great potential of the establishment of a Local Area Network. This implementation was accomplished by the IT department still within the vision of it being a technical support and maintenance provider, thus without any idea of enabling the flourishing of local (and later interconnected) clinical systems. 
Thus, the EPR paradigm exploited possibilities provided by the LAN paradigm. At the same time, the diffusion of PCs inside the hospital generated the flourishing of a myriad of local EPR and other clinical systems, which at the end hugely enriched the installed base of the information infrastructure, heavily influencing the course of the EPR implementation. In this very step, it is clear how on the one hand the EPR paradigm built on the previous one, yet on the other hand, the same infrastructure which allowed the EPR dream to be formalized, hampered the course of its implementation.

So far the influence of the past (the LAN paradigm and the infrastructure which it generated) and the dynamic of the present of the implementation of the EPR (the way it drifted away from plans producing delays and a long list of compromises) should be clear. We will now briefly analyze how the implementation of the EPR, and the paradigm in which it was conceived, heavily influenced the generation of the new paradigm for CSAM.

Similarly to the EPR, the CSAM vision was the by-product of an external shift of the technological paradigm. At that time the IT industry was strongly focused on the integration of existing systems. Accordingly, often the proposed technical solutions were a portal architecture, where the existing infrastructure of systems is loosely integrated with a layering strategy. Yet, the CSAM vision is not solely shaped by this new technical hype but it is largely the evolution of the EPR paradigm. In fact, each of the dimensions in the CSAM paradigm is the outcome of the experience accumulated with the EPR implementation. Indeed, the EPR had been the first attempt by the IT department to provide clinical systems with a hospital-wide scope. The people behind the CSAM vision were the same people who had been struggling for eight years in a particular management and technological paradigm (EPR) which they then thought was inappropriate. Most importantly, the new paradigm was not simply a change in a new direction with a fresh start. It is the opposite: it is the evolution in a new direction with the inertia and enrichment of the huge amount of knowledge and competence acquired in the previous paradigm. Examples of the paradigmatic shift enabled by this learning process are the change from a long-term to a shorter term strategy; or the evolution from a product to a process focus. Even clearer is the capitalization of knowledge about users and work practices from the EPR implementation, used to reorganize the role of users in the CSAM process (see Table 1).

From this perspective, the EPR innovation was both the (partial) realization of an infrastructural technology, and a huge learning process. The learning process resulted in the tangible confidence the IT department now has in addressing services for clinical information systems. It is also tangible in the installed base of (partly) standardized and centralized routines running 
on the EPR. This installed base represents a very important launching pad for CSAM like the LAN technology was for the EPR. Finally, but not least important, the implementation of the EPR created over the years a strong network of trust between the clinical departments and the IT department. Also in this case, the "installed base" of trust relationships represents an important starting point for the accomplishment of the CSAM vision.

\subsection{Limits of current studies}

We will now briefly discuss the literature reviewed in the theory section, and evaluate the usefulness of the proposed theoretical frameworks. Subsequently, we will point out how current theorizations tend to overlook the influence of an innovation on future innovations. We will conclude this exercize by pointing at some of the mentioned frameworks which could be used to open the analysis of innovation in the direction we are suggesting.

If we try to apply theories pertinent to the first research stream to the case, it will immediately become clear that almost each assumption and hypothesis made in those theories is hardly met. Not to say that such theories are not relevant: on the contrary. The mentioned theories simply are not adequate to the study of the innovation case presented in this paper. For instance, the model proposed by Cooper \& Zmud (1990) would be flawed by the excessive complexity of the technology (here intended as socio-technical network). The study of assimilation gaps by Fichman \& Kemerer (1999) would seem pointless as the deviation of deployment from the envisioned acquisition of the innovation would seem as a natural property of the trajectory of the infrastructure. Finally, any such theory based on a stage model would systematically fall short in describing the complexity of the innovation process. For one, in the model no account is given to the role of the installed base in shaping the innovation (if not for the negative connotations of something that needs to be changed). Nor does it take into consideration the fact that the innovation may remain open. According to each of these models the cycle of the innovation has to come to a final stage. This is certainly not the case of the innovation presented in this paper. While only about $40 \%$ of the EPR is implemented and operational, the remaining $60 \%$ is still under design, development, and testing.

If we turn to the second research-stream on IS innovation processes, we find at least two approaches which may be useful in the study of our case: studies on organizational learning (Attewell 1992; Ciborra \& Lanzara 1994; Argyris \& Schön 1996; Ciborra 1996) and studies adopting the theoretical framework of ANT (Latour 1987; McMaster et al. 1997; Monteiro \& Heps $\varnothing$ 1998; Aanestad \& Hanseth 2000). As illustrated previously in the paper, the change of paradigms may be interpreted as a learning process. As the 
mentioned theories on learning suggest, innovation as learning does not happen only as plain learning, or linear learning. In order to learn and innovate, people need to change their cognitive framework, formative context, or, finally, perform double-loop learning. While showing that the heritage of the past (in terms of e.g. formative context) influences the present nature of the innovation, such approaches tend to limit the study by identifying the innovation with the change to a different specific formative context (or set of values, or cognitive frame). For instance, the EPR paradigm entailed a new way of thinking, a new way of cooperating between departments, and a new way of looking at the technology. Nevertheless, the new formative context of the "organizing vision" (Swanson \& Ramiller 1997) of the EPR was not the only one generated by the lengthy implementation process. The new way of thinking in CSAM (which we want to identify as yet another formative context) is also an instance of the EPR innovation.

Similarly, studies using ANT are effective at describing the influence from existing network and the emergence from present implementation as complex and dynamic processes of enrolment, inscription and translation. They tend however to end the analysis at the point when the network is stabilized. In the context of an infrastructure, socio-technical networks (such as "hybrid collectifs") hardly stabilize and are hardly isolated. As a consequence, their emergent and interconnected nature continuously influences the surrounding context making it extremely difficult to draw the boundaries between one innovation and the next. We sustain that the cited literature comes short in highlighting this aspect.

In conclusion, we submit that theories from the first research stream have a structural limitation which does not allow them to be used outside the given spatial and temporal boundaries. Whereas regarding the second research stream, theories on learning and studies using ANT seem to have the adequate methodological and analytical framework to investigate beyond those boundaries, but their application seems to be intentionally limited.

An exception to the proposed theories is the concept of path creation (Garud \& Karnøe 2001). Path creation is a concept developed exactly to address the importance of being aware that present innovations will have a path dependent influence on the future trajectory. While this intuition is extremely relevant, its application to the study of innovation in IS seems to be lacking and should thus be developed.

\subsection{Temporal disclosedness of innovations}

In this paragraph, in light of the collected and analyzed empirical evidence, we will introduce the concept of temporal disclosedness of 
innovations in information infrastructures (Heidegger 1962). The aim of introducing this concept is to highlight a peculiar characteristic of innovations occurring in complex infrastructures of interconnected IS: as illustrated in the case, once implemented, it becomes extremely difficult to draw temporal and spatial boundaries around the innovation.

If implementation of the innovation usually means the realization of predetermined possibilities in time, temporal disclosedness of the innovation means that the implementation is dealing with possibilities beyond the traditional time and space occupied by the implementation process; i.e. before the implementation starts, as the implementation unfolds, and beyond the completion (or incompletion) of the implementation.

With regard to the past and the present, the concept of temporal disclosure is near to other concepts highlighted in the theoretical section (from path dependency and installed base, to improvisation, interaction, and emergence). The concept proposed here is particularly relevant in that it also extends the perspective on the future evolution trajectory of the infrastructure.

\subsubsection{Disclosure of the past}

Temporal disclosure of the past refers to how phenomena such as path dependency, lock-in, and formative contexts of the existing installed base provide pre-existing possibilities and inertia with which the innovation has to deal. Disclosure means that the innovation is already-there in the possibilities allowed or precluded by the installed base which wait to be disclosed.

\subsubsection{Disclosure of the present}

Temporal disclosure of the present refers to how the complexity of the infrastructure affects the implementation as it unfolds: it drifts, it becomes emergent, interactive, renegotiated, and reinvented. Thus, compared to a view on implementation as awating of the realization of predetermined possibilities, implementation becomes also anticipation of new possibilities through improvisation, tinkering, and bricolage (Heidegger 1962; Ciborra 1999).

\subsubsection{Disclosure of the future}

As the influence of the EPR paradigm in the conception of CSAM shows, the innovation becomes part of the installed base shaping and triggering new innovations. Temporal disclosure of the future means that the new 
possibilities are not only regarding the implementation of the current innovation, rather they may affect the conception of new and future innovations.

\subsubsection{Temporal disclosedness of innovations}

Temporal disclosedness of innovations in information infrastructures means that the lifecycle of an infrastructural innovation is not closed in time boundaries defining its possibilities; it is rather disclosed along the entire past and future trajectory

Based on this characteristic, we propose that the analysis of future influence of the innovation on the trajectory of the infrastructure is not a matter of choice, rather a methodological imperative. This implies that the evaluation of an innovation in an infrastructure should also consider the influence of the innovation at case on the implementation of later innovations. For instance, the evaluation of the EPR should include an analysis of the influence of the EPR on the generation and implementation of CSAM. We also suggest that theories from the process-model research stream may provide adequate analytical and conceptual tools (particularly theories on learning and ANT). Yet, limiting the analysis to the particular apparent lifecycle of an innovation may be useful but it risks giving the wrong impression that innovations in such complex settings can be analytically isolated in time and space. In our case, evaluating the EPR innovation considering or not considering its influence on CSAM would bring different results. At first it could appear as a failure. At second analysis it is possible to observe the tangible (and unpredicted) benefits brought to the CSAM innovation.

More provokingly, when studying innovations in information infrastructure, one should not be fooled by the apparent suitability of spatial and temporal categories of the innovation. To understand the particular innovation, one is forced to understand also the surrounding context in which it is embedded and analyze it in an historical perspective including past and future.

\section{CONCLUDING REMARKS}

In this paper, we have addressed the question of how to conceptualize temporal aspects of IS innovations occurring in complex infrastructures of interconnected information systems. Using the framework of Information Infrastructure (Hanseth et al. 1996), we have adopted a view on information technology in organizations which acknowledges the complex dynamics of 
its trajectory. We have then reviewed current literature on the study of innovation processes in the field of IS, highlighting different perspectives and shortcomings in the analysis of temporal aspects of innovations. In particular, we have illustrated how there is a general lack of study on the influence of the implemented innovation on the future trajectory of the infrastructure. With the help of a case study based on an IS innovation implemented in a hospital, we have shown how it is paramount to study such influence. In order to sustain this argument and based on the evidence of the case, we have introduced the concept of temporal disclosedness of the innovation. This concept is useful to understand the limits of current conceptualizations of innovation processes in complex infrastructures. The limits, which we suggest should be overcome, refer to the tendency of keeping a temporally closed view on the innovation. This view, we sustain, veils the nature of the innovation phenomenon, which, on the contrary, tends to become temporally disclosed along the entire trajectory of the infrastructure.

\section{REFERENCES}

Aanestad M., Hanseth O.. (2000), "Implementing open network technologies in complex work practices. A case from telemedicine". In Proceedings from IFIP WG 8.2 International Conference. The Social and Organizational Perspective on Research and Practice in Information Technology, June 10-12, 2000, Aalborg, Denmark

Antonelli, C., (1992), "The economic theory of information networks". In The Economics of Information Networks, ed. C. Antonelli, North-Holland, 1992.

Argyris C., Schön D.A., (1996), Organizational Learning II, Addison-Wesley, Reading, Mass., 1996.

Arthur, W.B., (1989), "Competing technologies, increasing returns, and lock in by historical events", Economic Journal 99: 116-131, 1989.

Arthur W.B., (1994), Increasing Returns and Path Dependency in the Economy, The University of Michigan Press.

Attewell P., (1992), "Technological Diffusion and Organizational Learning: The Case of Business Computing", Organization Science, Vol. 3, Issue 1 (Feb., 1992), pp. 1-19.

Baskerville R., Pries-Heje J., (1997), "IT diffusion and innovation models: the conceptual domains", in Facilitating Technology Transfer through Partnership: learning from practice and research, Proc. IFIP TC8 WG8.6 Conference, Tom McMaster Enid Mumford E.Burton Swanson Brian Warboys and David Wastell (eds.), Kluwer Academic Publisher.

Ciborra C.U., Lanzara G.F., (1994), "Formative Contexts and Information Technology: Understanding the Dynamics of Innovation in Organizations", Accounting Management and Information Technology, Vol. 4, No. 2, pp. 61-86, 1994.

Ciborra C.U., (1996), "What does Groupware Mean for the Organizations Hosting it?", in Groupware and TeamWork: Invisible Aid or Technical Hindrance?, Claudio U. Ciborra ed., John Wiley \& Sons, pp. 1-19.

Ciborra, C., (1999), "Notes on Improvisation and Time in Organizations", Accounting, Management and Information Technologies 9 (1999). 
Ciborra, C., Braa, K., Cordella, A., Dahlbom, B., Failla, A., Hanseth, O., Hepsø, V., Ljungberg, J., Monteiro, E., Simon, K., (2000), From Control to Drift. The Dynamics of Corporate Information Infrastructures, Oxford University Press, 2000.

Ciborra C. U., (2002), The Labyrinths of Information - Challenging the Wisdom of Systems, Oxford University Press

Cooper R. B., Zmud R.W., (1990), "Information Technology Implementation Research: A Technological Diffusion Approach", Management Science, Vol. 36, No. 2 (Feb. 1990), pp. 123-39.

Damsgaard J., Lyytinen K., (1997), "Hong Kong's EDI bandwagon: derailed or on the right track?", in Facilitating Technology Transfer through Partnership: learning from practice and research, Proc. IFIP TC8 WG8.6 Conference, Tom McMaster Enid Mumford E.Burton Swanson Brian Warboys and David Wastell (eds.), Kluwer Academic Publisher.

David P., (1985), "Clio and the economics of QWERTY", American Economic Review, Vol. 75 (1985), Issue 2 (May), pp. 332-37.

Dosi G., (1982), "Technological paradigms and technological trajectories: a suggested interpretation of the determinants and directions of technical change", Research Policy, Vol. 11 (1982), pp. 147-62.

Fichman R.G., Kemerer C.F., (1999), "The Illusory Diffusion of Innovation: An Examination of Assimilation Gaps", Information Systems Research, Vol. 10, No. 3, September 1999, pp. 255-75.

Gallivan M.J., (2001), "Organizational Adoption and Assimilation of Complex Technological Innovations: Development and Application of a New Framework", The DATA BASE for Advances in Information Systems, Summer 2001, Vol. 32, No. 3, pp. 51-85.

Garud R., Karnøe P., (2001), Path Dependence and Creation, Lawrence Erlbaum Associates Publishers

Hanseth O., Monteiro E., Hatling M., (1996), "Developing information infrastructure: The tension between standardization and flexibility". Science, Technology and Human Values. Vol. 21 No. 4, Fall 1996, 407-426.

Heidegger M., (1962), Being and Time, Blackwell Publisher Ltd.

Henfridsson O., (1999), IT-adaptation as sensemaking: inventing new meanings for technology in organizations, Ph.D. Thesis, Department of Informatics, Umeå University, Sweden.

Klein, H.K., and Myers, M.D., (1999), "A set of principles for conducting and evaluating interpretive field studies in information systems", MIS Quarterly, vol.23, no.1, 1999, pp.67-93.

Kwon T.H., Zmud R.W., (1987), "Unifying the fragmented models of information systems implementation", in Critical Issues in Information Systems Research, R.J. Boland and R.A. Hirschheim eds., John Wiley \& Sons, pp.227-51.

Langley A., (1999), "Strategies for theorizing from process data", Academy of Management Review, 1999, Vol. 24, No. 4, 691-710.

Latour B., (1987), Science in Action, Harvard.

Leonard-Barton D., (1988), "Implementation as mutual adaptation of technology and organization", Research Policy, Vol. 17 (1988), pp. 251-67.

Lewin K., (1952), "Groups Decision and Social Change", in Readings in Social Psychology, Newcombe and Hartley (Eds.), Henry Holt, New York, pp. 459-73.

Lyytinen K., Damsgaard J., (2001), "What's wrong with the Diffusion Of Innovation Theory?", in Diffusing Software Product and Process Innovations, Proc. IFIP TC8 WG8.6 Conference, Ardis M.A., Marcolin B.L. (eds.), Kluwer Academic Publisher. 
McMaster T., Vidgen R.T., Wastell D.G., (1997), “Technology Transfer - diffusion or translation?", in Facilitating Technology Transfer through Partnership: learning from practice and research, Proc. IFIP TC8 WG8.6 Conference, Tom McMaster Enid Mumford E.Burton Swanson Brian Warboys and David Wastell (eds.), Kluwer Academic Publisher.

Monteiro E., Heps $\varnothing$ V., (1998), "Diffusion of infrastructure: mobilisation and improvisation", In Information systems: current issues and future challenges, Proc. IFIP WG $8.2 \&$ 8.6, T. Larsen L. Levine (eds.), IFIP 1998, pp. 255 - 274.

Newell, S., Swan, J.A., Robertson M., (1998). "A cross-national comparison of the adoption of BPR: An interactive perspective”. 31st International Conference on Systems Sciences, IEEE Computer Society Press.

Newell, S., Swan, J.A., Galliers R.D.. (2000). "A knowledge-focused perspective on the diffusion and adoption of complex information technologies: The BPR example." Information Systems Journal 10: pp.239-259.

Robertson, M., Swan, J., Newell S. (1996). "The role of networks in the diffusion of technological innovation." Journal of Management Studies 33(3): pp.333-359.

Rogers E.M., (1995), Diffusion of Innovations, $4^{\text {th }}$ Edition, Free Press.

Rothwell, R. (1994) Towards the fifth generation innovation process. International Marketing Review, 11, 7-31.

Swanson E.B., Ramiller N.C., (1997), "The Organizing Vision in Information Systems Innovation", Organization Science, Vol. 8, Issue 5 (Sep.-Oct., 1997), pp. 45874.

Van de Ven A.H., (1986), "Central Problems in the Management of Innovation", Management Science, Vol. 32, No. 5, Organization Design (May, 1986), pp. 590-607.

Walsham, G., (1993), Interpreting Information Systems in Organizations, Wiley, 1993.

Walsham, G., (1995), "Interpretive case study in IS research: nature and method", European Journal of Information Systems, Vol.4, 1995, pp.74-81.

Weick K.E., (1995), Sensemaking in Organizations, Thousand Oaks: Sage.

Wolfe R A., (1994), "Organizational Innovation: Review, Critique and Suggested Research Directions", Journal of Management Studies, 31:3, May 1994, pp. 405-31. 